\title{
Workshop on Information and Public Relations
}

During the Varna Festival, 56 persons responsible for the information departments of 29 National Societies and those of the ICRC and the League participated in a two-day workshop. The purpose of this meeting, chaired in turn by Mr. Alain Modoux, head of the Department of Information of the ICRC, and Mr. George Reid, his counterpart in the League, was an exchange of views on the whole range of problems confronting the Movement in the field of information and public relations, particularly with regard to multilateral and bilateral co-operation. Other subjects were also discussed, such as the development of information, public relations and dissemination activities by National Societies, new communication technology, the role of National Societies in efforts to prevent the spread of AIDS, as well as questions relating to audio-visual productions.

At the end of their meeting, the participants unanimously adopted ten recommendations which the representatives of the ICRC and the League were asked to submit to the Council of Delegates at its next meeting, in Rio de Janeiro in November 1987. They recommended that:

- National Societies, the League and the ICRC should step up exchanges of written and audio-visual material.

- In case of natural or man-made disaster, while taking the time factor into account, the League and the ICRC should send information from Geneva directly to the specific persons in charge of information and public relations in the National Societies. They should work in close co-operation with international news, photo and television agencies to ensure that in the case of large-scale disasters these agencies use their networks to distribute news, photos and TV pictures of Red Cross operations worldwide.

- The League and the ICRC should produce basic audio-visual material, such as short video clips and slides, which could be adapted and used by each National Society as needed.

- The National Societies should participate in the next poster competition of the Alliance of Red Cross and Red Crescent Societies of the 
USSR, scheduled for 1989, with the support of the ICRC and the League.

- The League and the ICRC should prepare a collection of case histories demonstrating in concrete terms the way information and public relations services have dealt with emergencies and situations of crisis.

- The League and the ICRC should make greater use of the Spanish language in their publications and send more Spanish-speaking journalists to theatres of operations.

- The League should henceforth consult with the ICRC in choosing the theme and making preparations for World Red Cross and Red Crescent Day (8 May).

- In all messages sent out by the Red Cross and Red Crescent, a systematic linkage should be established between information concerning the activities of the Movement and dissemination of its fundamental Principles and ideals.

- The League and the ICRC should draw up, together with the National Societies concerned, a programme of concrete and co-ordinated action designed to help newly developing National Societies in their efforts to launch and/or expand their activities in the spheres of information, public relations and dissemination.

- Every two years the League and the ICRC should organize within the framework of the Varna Festival a meeting of persons in charge of information and public relations in the National Societies-alternating with biennial regional meetings - so that they can share their experiences and develop multilateral and bilateral co-operation. 